\title{
GEISTIGE STRÖMUNGEN
}





\title{
GEISTIGE STRÖMUNGEN DER GEGENWART
}

\author{
Von \\ Rudolf Eucken
}

Der Grundbegriffe der Gegenwart sechste umgearbeitete Auflage

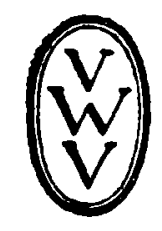

BERLIN UND LEIPZIG 1920

VEREINIGUNG WISSENSCHAFTLICHER VERLEGER WALTER DE GRUYTER \& CO.

VORMALS G. J. GOSCHEN'SCHE VERLAGSHANDLUNG :: J. GUTTENTAG, VERLAGSBUCHHANDLUNG :; GEORG REIMER :; KARL J. TRUBNER ;: VEIT \& COMP. 
Alle Rechte, einschlie日lich des Übersetzungsrechts, vorbehalten.

Druck von Gerhard Stalling in Oldenburg. 